\title{
Hip Stability Parameters with Dual Mobility, Modular Dual Mobility and Fixed Bearing in Total Hip Arthroplasty: an Analytical Evaluation.
}

\section{Domenico Tigani}

Ospedale Maggiore Carlo Alberto Pizzardi

\section{Lorenzo Banci}

Permedica Spa

Riccardo Valtorta

Permedica Spa

Luca Amendola ( $\square$ luca.amendola@yahoo.it)

Ospedale Maggiore Carlo Alberto Pizzardi https://orcid.org/0000-0003-2052-4437

\section{Research article}

Keywords: dual mobility cup, modular dual mobility cup, fixed bearing cup, jumping distance, total hip arthroplasty dislocation

Posted Date: September 7th, 2021

DOI: https://doi.org/10.21203/rs.3.rs-864696/v1

License: @ (i) This work is licensed under a Creative Commons Attribution 4.0 International License. Read Full License 


\section{Abstract}

Background. Use of dual mobility in total hip arthroplasty has gained popularity due to the ability to reduce dislocation through increased jumping distance and impingement-free arc of movement. Recently, modular dual mobility systems were introduced to give the possibility to use dual mobility with standard metal-backed shells, however few has been studied to date regarding how jumping distance and the center of rotation changed with modular dual mobility. The objective of this study was to evaluate, through analythical simulation, how jumping distance and center of rotation change between dual mobility and standard cup with modular dual mobility or fixed bearings.

Methods. 3D-models of dual mobility and standard press-fit cups with modular dual mobility or fixed bearings liners were used to simulate dual mobility, modular dual mobility and fixed bearings implant configurations, matched for same cup size, according to same cup position, different femoral head diameters. Jumping distance was calculated and center of rotation lateralization was measured for different sizes.

Results. Jumping distance with modular dual mobility was reduced by $-3.9 \mathrm{~mm}$ to $-8.6 \mathrm{~mm}$ in comparison with dual mobility, from 48 to $64 \mathrm{~mm}$ sizes. Jumping distance with modular dual mobility resulted comparable to jumping distance with polyethylene fixed bearings with $\varnothing 36 \mathrm{~mm}$ femoral head but increased by $+1.1 \mathrm{~mm}$ and $+1.4 \mathrm{~mm}$ than jumping distance with ceramic fixed bearings with $\varnothing 36$ and $\varnothing 40 \mathrm{~mm}$ femoral heads for sizes $>54 \mathrm{~mm}$. Modular dual mobility lateralized the center of rotation up to $+2.5 \mathrm{~mm}$ and $+4.0 \mathrm{~mm}$ in comparison with dual mobility and fixed bearings, respectively.

Conclusions. Jumping distance with modular dual mobility resulted lower than dual mobility and comparable to fixed bearings polyethylene liner with $\varnothing 36 \mathrm{~mm}$ femoral head for larger sizes. Modular dual mobility lateralized the center of rotation in comparison with both dual mobility and fixed bearings cups.

\section{Background.}

Instability after total hip arthroplasty (THA) continues to be one of the leading causes of early revision and the first reason for failure after revision THA [1].

Risk factors for early dislocation include patient-related and surgical-related factors as well as factors linked to the implant. Although multifactorial, it is well accepted that stability in THA improves with larger-sized femoral heads [2, 3]. Reasons supporting use of larger femoral heads are primarily the ability to provide a wider impingement-free range of movement and increased jumping distance (JD) [4, 5].

Dual mobility (DM) concept was developed and introduced in THA in 1974 in order to reduce postoperative hip instability $[6,7]$. The idea of a dual articulation was to combine Charnley's low friction principle to reduce polyethylene wear by small diameter femoral heads [8] with the Mckee-Farrar concept of using larger diameter femoral heads to enhance hip stability [9]. DM has been reported to be effective in decreasing the risk of postoperative instability both in primary and revision THA [10].

In the last decade the introduction of a modular metal inlay allowed the use of a DM liner with a press-fit metalbacked shell for an "hybrid" modular DM (modDM) THA in high-risk patients for hip dislocation. 
To date, modDM acetabular systems are providing excellent results with rare dislocations after revision THA [11, 12]. Recently, several studies are reporting on metal release caused by the modularity of DM inlay, showing acceptable blood metal levels [13-15]. However, no data has been published so far regarding biomechanical differences in terms of JD and center of rotation (CR) position between conventional DM and modDM systems.

The objective of this study was to evaluate, through an analythical 3D-modelling simulation, how JD and CR change considering DM, modDM and fixed bearing (FB) cups, matched for same cup size, according to same cup position, different head diameters and femoral head offset.

\section{Methods.}

\section{Definition of the parameters}

A Cartesian reference landmark was defined: $\mathrm{O}$ was the center of the cup, $\mathrm{Oz}$ was the cranio-caudal axis, $\mathrm{Oy}$ was the lateral-medial axis, and $\mathrm{Ox}$ the postero-anterior axis.

JD is defined as the lateral translation distance of the femoral head center (CR) required for a head to dislocate from a socket (Figure 1). We used the formula by Sariali [16], reported below, to calculated JD, which is a function of 4 variables: $a, b$, $R$, offset.

\section{$J D=2 R \sin [(\pi / 2-\Psi-\arcsin ($ offset/R)) /2]}

Where:

$\Psi$ is the planar cup inclination angle measured on the frontal plane by using the following formula and corresponds to the projection of the abduction angle (a) on the frontal plane.

\section{$\Psi=\arctan [\tan (\alpha) \times \cos (\beta)]$}

$\alpha$ is the cup abduction angle.

$\beta$ is the cup anteversion angle on the cross-sectional plane.

$R$ is the radius of the femoral head.

Offset is the femoral head offset and it is defined as the distance between the femoral head center (CR) and the cup opening plane. If the femoral head center is located inside the cup, the offset has negative value (femoral inset), whereas, if it is located outside the cup, the offset has positive value (Figure 2).

Knowing from Sariali that JD changes in function of cup abduction and anteversion angles, we decided to set the acetabular cup orientation with constant abduction angle (a) of $45^{\circ}$ and constant anteversion angle (b) of $15^{\circ}$, which are within the safe zone described by Lewinnek et al.[17].

Lateralization or medialization of the CR were defined as lateral or medial shift of the CR on frontal plane when using modDM or FB in comparison with DM, as reference. 


\section{Prosthetic implants}

All acetabular components used for this study were from the same manufacturer (Permedica Orthopaedics S.p.A.,Merate,ttaly), in order to exclude product design variability between different brands from different manufacturers.

We studied two cementless press-fit acetabular cups which both featured a highly-porous random trabecular titanium structure, commercially named Traser ${ }^{\circledR}$, manufactured by selective laser melting technology without solution of continuity on the bone-implant side of the cup.

The first implant was a conventional DM cup, named Acorn Traser ${ }^{\circledR}$ DM cup, with polar-flatted hemispherical profile, $0^{\circ}$ cup opening plane and $2.5 \mathrm{~mm}$ cylindrical equatorial extra-coverage. The $\mathrm{CR}$ of the femoral head had a medial eccentricity from the center of the polyethylene mobile liner.

The second implant was a standard titanium alloy press-fit modular cup, named Jump System Traser® cup, with a polar-flatted hemispherical profile which allowed for polyethylene or ceramic FB to be coupled with $\varnothing 28 \mathrm{~mm}, 32 \mathrm{~mm}, 36 \mathrm{~mm}$ and $40 \mathrm{~mm}$ femoral heads or for modDM inlay to be articulated with the same DM liner of the Acorn Traser ${ }^{\circledR}$ DM cup.

\section{Methods}

For measuring the distances of interest, the following landmarks were considered:

A: Center of DM liner.

C: Center of femoral head (CR).

D: Center of the ideal spherical cup outer profile.

E: intersection point between the cup opening plane and cup axis.

Offset was defined as the distance $\mathbf{A E}$ in case of DM and modDM, while as the distance $\mathrm{CE}$ in case of FB. Due to the medial eccentricity of the femoral head CR with DM and modDM, we used the center of the polyethylene mobile liner (A) as offset landmark, because when dislocating from the shell, the mobile liner acts like femoral head. $\mathbf{R}$ was the radius of the polyethylene mobile liner in case of DM and modDM, while the radius of the femoral head in case of FB (Figure 3).

To calculate the $\mathrm{CR}$ position change, it was measured the distance $\mathrm{CD}$ between the $\mathrm{CR}(\mathrm{C})$ and the geometric center (D) of the ideal spherical profile which better outline the outer profile of cup equatorial portion (Figure 3). This our convention was taken to choose a common landmark of the acetabular implant, in order to exclude design differences between DM cup and standard cup. The geometric center (D) of the ideal spherical cup profile, in fact should correspond to the center of the cup when achieving press-fit fixation into the acetabular cavity, leaving a more or less pronounced polar gap between the acetabular floor and the polar apex of the cup $\left(D^{\prime}\right)$. Thus, this center (D) approximately corresponds to the same landmark point referred to the acetabulum 
when implanting same-sized acetabular cups of different design. CD is then adjusted taking into account the cup frontal abduction angle $\Psi$, multiplying by $\cos \Psi$.

Technical 3D-models of the prosthetic components were used to simulate three configurations of acetabular implants: DM, modDM and FB, matched for same cup size (external diameter) in the range from size $\emptyset 48 \mathrm{~mm}$ to size $\varnothing 64 \mathrm{~mm}$, which allowed the use of a $28 \mathrm{~mm}$ femoral head diameter (Table 1 ).

In particular, DM cup was graphically coupled with DM liner and $\varnothing 28 \mathrm{~mm}$ femoral head and then offset $\mathrm{AE}$ and distance CD were measured (Figure 3A).

Similarly, standard cup was graphically coupled with modular DM liner, DM liner and Ø28mm femoral head and offset $\mathbf{A E}$ and distance $\mathbf{C D}$ were then measured (Figure 3B).

Last, same standard cup was graphically coupled with $0^{\circ}$ polyethylene or ceramic FB and different femoral head diameters according to the available matching (Table 1) and offset $\mathrm{CE}$ and distance $\mathrm{CD}$ were measured (Figure 3C).

Lateralization or medialization of the $\mathrm{CR}$ when using modDM (or FB) were defined as the difference between $\mathrm{CD}$ with modDM (or with $\mathrm{FB}$ ) and $\mathrm{CD}$ with $\mathrm{DM}$.

Graphical implant simulations were performed and distances of interest were measured by using modeling and drafting tools of software CAD NX Siemens 7.5, 2010.

\section{Results.}

\section{Jumping distance}

AE distance in DM changed from $-2.4 \mathrm{~mm}$ with smallest cup size to $-1.9 \mathrm{~mm}$ with largest size. Thus, the center of the DM liner (A) was located always within the DM shell, medially from the cup opening plane, so DM shell had a slightly decreasing inset as size increased (Table 2). The resulting JD with DM linearly increased as size increased from $17.8 \mathrm{~mm}$ to $23.7 \mathrm{~mm}$ (Figure 4).

AE distance in modDM changed from $+1.0 \mathrm{~mm}$ with smallest cup size to $+3.0 \mathrm{~mm}$ with largest size. Thus, the center of the DM liner (A) was located outside the shell, laterally, from the cup opening plane, so modDM cup showed an increasing offset as size increased (Table 2). JD with modDM slightly increased from $13.9 \mathrm{~mm}$ to $15.3 \mathrm{~mm}$ up to $56 \mathrm{~mm}$ cup size, then remained approximately constant to $15.1 \mathrm{~mm}$ (Figure 4).

CE distance in polyethylene FB was set constant to $-1 \mathrm{~mm}$ as being design parameter for all femoral head diameters (Table 2). JDs with polyethylene FB coupled with $28 \mathrm{~mm}, 32 \mathrm{~mm}, 36 \mathrm{~mm}$ and $40 \mathrm{~mm}$ femoral head diameters resulted $11.8 \mathrm{~mm}, 13.4 \mathrm{~mm}, 15.0 \mathrm{~mm}$ and $16.6 \mathrm{~mm}$ respectively, constantly per size (Figure 4 ).

CE distance measured for ceramic FB cup were $-1 \mathrm{~mm}$ for $\varnothing 28 \mathrm{~mm}$ and $32 \mathrm{~mm}$ femoral heads, $0 \mathrm{~mm}$ for $\varnothing 36 \mathrm{~mm}$ and $+2 \mathrm{~mm}$ for $\varnothing 40 \mathrm{~mm}$, as constant design parameter (Table 2). JDs with ceramic FB coupled with $28 \mathrm{~mm}$, $32 \mathrm{~mm}, 36 \mathrm{~mm}$ and $40 \mathrm{~mm}$ femoral head diameters resulted $11.8 \mathrm{~mm}, 13.4 \mathrm{~mm}, 14.0 \mathrm{~mm}$ and $13.7 \mathrm{~mm}$, respectively, constantly per size (Figure 5). 
JD with modDM was reduced by $-3.9 \mathrm{~mm}$ to $-8.6 \mathrm{~mm}$ in comparison with DM cup, from $48 \mathrm{~mm}$ to $64 \mathrm{~mm}$ cup size. JD with modDM resulted comparable to JD with polyethylene FB cup with $36 \mathrm{~mm}$ femoral head diameter for cup sizes $>54 \mathrm{~mm}$. However, JD with modDM slightly increased by $+1.1 \mathrm{~mm}$ and $+1.4 \mathrm{~mm}$ than JD with ceramic FB cup with $36 \mathrm{~mm}$ and $40 \mathrm{~mm}$ femoral head diameters for cup sizes $>54 \mathrm{~mm}$.

\section{CD distance and CR position}

CD distances for DM, modDM and FB with all femoral head diameters were showed per cup size increase in Figure 6. CD with DM slightly increased from $+0.5 \mathrm{~mm}$ to $+0.8 \mathrm{~mm}$. CD with modDM periodically changed from $+3.1 \mathrm{~mm}$ to $+0.7 \mathrm{~mm}$. CD with FB coupled with $\varnothing 28 \mathrm{~mm}$ and $\varnothing 32 \mathrm{~mm}$ heads decreased from $+0.9 \mathrm{~mm}$ to $-1.7 \mathrm{~mm}$, for both polyethylene and ceramic liners. CD with $\varnothing 36 \mathrm{~mm}$ and $\varnothing 40 \mathrm{~mm}$ heads coupled with polyethylene liners showed a similar decreasing trend. CD with ceramic FB and $\varnothing 36 \mathrm{~mm}$ head decreased from $+1.0 \mathrm{~mm}$ to $-1.0 \mathrm{~mm}$, while CD with ceramic FB and $\varnothing 40 \mathrm{~mm}$ head decreased from $+1.5 \mathrm{~mm}$ to $+0.4 \mathrm{~mm}$.

Use of modDM involved a lateralization of the CR which ranged from +0.1 up to $+2.5 \mathrm{~mm}$ depending on size in comparison with DM cup (Figure 6). Again, modDM led to a further lateralization of the CR in comparison with FB cup, ranging from $+1.4 \mathrm{~mm}$ up to $+4.0 \mathrm{~mm}$ depending on size. Lateralization of $\mathrm{CR}$ with modDM even occurred in comparison with $36 \mathrm{~mm}$ and $40 \mathrm{~mm}$ femoral head diameters (Figure 6).

\section{Discussion.}

After THA, hips with less JD are theoretically more susceptible to dislocate than hips with more JD. Our findings confirmed that conventional DM cups provide better joint stability achieving higher JD in comparison with modDM systems, at same cup size and same cup position. JD with DM linearly increased with increasing of cup size, similarly to the results reported by Sariali. Conversely, JD with modDM was lower in comparison of DM and maintained almost constant as size increased.

Thus, using larger DM cups, it is possible to guarantee higher JD, so, better hip stability. However, this finding is not replicable with modDM systems which keep JD constantly lower, whatever size of cup is used. The reason could be found looking at the formula by Sariali.

The equation highlights that JD depends not only on femoral head size, but also on orientation of the implanted cup and the femoral head offset. JD is mainly affected by the cup abduction angle than anteversion angle [16, 18]. With constant cup abduction and anteversion angles, JD is directly related to femoral head size and inversely related to head offset, which is the geometrical factor that has the highest influence on JD [16]. Offset can have a positive value or a negative value (inset). In case of negative sign, as with DM, an inset increase, in absolute value, leads to JD increase. Conversely, in case of positive sign, as with modDM, an offset increasing leads to JD decreasing and, no matter how $\mathrm{R}$ increases, JD remains low. So, in our simulation, offset progressively increased per cup size increase with modDM and keep JD low in comparison with DM where, instead, offset progressively decreased but remaining always negative (inset), thus increasing JD.

Regarding to polyethylene FB cup with $28 \mathrm{~mm}, 32 \mathrm{~mm}, 36 \mathrm{~mm}$ and $40 \mathrm{~mm}$ femoral head diameters, JD changed according to Sariali, increasing with femoral head size increase, because femoral head offset was set constant for each size as being a design parameter (Table 2). 
JD with DM cup resulted higher than JD with FB coupled with all femoral head diameters per each cup size. Interestingly, JD with modDM resulted very similar to JD with polyethylene FB cup coupled with Ø36mm femoral head for sizes $\geq \varnothing 56 \mathrm{~mm}$ but, on the contrary, JD with modDM resulted lower for sizes smaller than $\varnothing 56 \mathrm{~mm}$ (Fig. 4).

But with ceramic liners is inverted with larger sizes. JD with ceramic FB coupled with $36 \mathrm{~mm}$ and $40 \mathrm{~mm}$ femoral head diameters decrease for sizes $\geq \varnothing 56 \mathrm{~mm}$ in comparison with modDM (Fig. 5). The use of large heads requires an offset increase that reduce JD [18]. For a 1-mm increase in head offset, JD is decreased by $0.92 \mathrm{~mm}$. This is why use of very large femoral heads leads to a moderate JD increase than expected and this could be one possible reason to explain high dislocation rates reported in revision THA with femoral heads larger than 36-mm diameter [19]. Recently, in a study of patients undergoing revision THA for a variety of reasons, Hartzler et al. found a lower rate of patients who dislocated postoperatively when revised to a modular dual-mobility construct compared with those revised with a large 40-mm femoral [20].

Our findings showed how the use of modDM system leads to a lateral deviation of the CR in comparison with DM cup and this CR lateralization is more or less evident depending on cup size. The dimensions of both modDM liner and acetabular cup for every size largely affected CD distance. As showed in Table 1, modDM liner sizes are matched with cup sizes in a 1:2 or 1:3 ratio, explaining the CD variability with modDM system with size increasing.

To date, the use of modDM provided excellent results in terms of dislocation incidence. A large matched cohort single-center study comparing modDM and standard DM reported for both groups $0 \%$ of dislocation after primary THA at a mean follow-up of 2.8 years [11].

A retrospective case-series study of modDM cups used in revision THA found a dislocation prevalence of $3.1 \%$ after 3-year average follow-up [21]. Another recent multicenter retrospective study reported a similar dislocation rate $(2.9 \%)$ after revision THA in a large cohort of patients treated with modDM [12].

The use of modDM is not risk-free but, conversely, involves more potential complications than conventional DM. modDM is a prosthetic construct which adds one more modular cobalt-chromium liner. The fretting and crevice corrosion at the non-articulating metal-on-metal interface between the modular liner and the titanium socket cause an extra metal release in comparison with conventional DM [22-24].

In literature several studies reported uniformly low blood metal ions concentrations in patients undergone modDM primary or revision THA, which were found to be acceptable for the safety of patients [13-15]. However, all these studies reported short follow-ups and it is unknown to date the possible adverse biological effects of metal release in the long-term. Metal release from metal modularity thus still remain a cause for concern that need to be continuously surveilled.

Use of modDM implicates also the risk of modular metal liner malseating which is reported with an incidence up to $5.8 \%$. Liner malseating may lead to increased fretting corrosion and metal related issues, component dissociation and reduced stability $[25,26]$.

Thus, the use of the modDM should be indicated in complex primary THA and revision THA and should be limited to those high-risk patients where the use of conventional DM cup is not recommended or even not 
feasible. Typical cases indicated to use of modDM are, for instance, severe hip dysplasia or high hip dislocation, patients at high risk of dislocation with poor pelvic bone quality that requires a further cup stabilization with additional bone screws into shell holes, revision THA for recurrent instability when it is required to replace the acetabular liner with a modDM liner in a well-osseointegrated cup.

Facing these considerations modDM should not be used as the first choice instead of a DM but rather when required or when modDM can solve intraoperatively a problem.

\section{Study limitations.}

The major limitation of the present study was that the analysis performed for JD and lateralization of the CR were strictly dependent on the design technical specifications of the studied prosthetic components. Even if the take-home message from the present study is suitable for DM and modDM THA, the authors did not exclude design-related differences between different DM cups and modDM systems currently available on the market. Therefore, the results from the present study were valid for the studied components but may change with other devices.

The focus of this investigation was on hemispherical or cylindrical-extended hemispherical cups which are both designed for standard and DM THA. In the past JD changes were studied according to femoral head offset, head size and cup position [16]. However, these studies evaluated only standard implants and subhemispherical cups for large head diameters (above $38 \mathrm{~mm}$ ), specifically designed for metal-on-metal implants, which have a negative effect on JD, due to their smaller coverage angle and higher head offset $[27,28]$.

\section{Conclusions.}

Hip stability after THA in terms of JD with use of modDM systems is lower than conventional DM cups and comparable to cups with fixed polyethylene liner articulating against $\varnothing 36 \mathrm{~mm}$ and $\varnothing 32 \mathrm{~mm}$ femoral heads, respectively for larger and smaller cup sizes. Moreover, modDM systems lateralize the $\mathrm{CR}$ in comparison with both conventional DM and FB cups with different femoral head diameters. These results should be kept in mind when using modDM systems in those high-risk patients for instability suggesting that modDM should be indicated only when conventional DM cups are not feasible or contraindicated.

\section{Abbreviations}

THA: Total hip arthroplasty

DM: Dual Mobility

JD: Jumping Distance

ModDM: Modular Dual Mobility

CR: Center of Rotation

FB: Fixed bearings 


\section{Declarations}

\section{Ethics approval and consent to participate}

This article does not contain any studies with human participants or animals performed by any of the authors.

\section{Consent for publication}

Not applicable.

\section{Availability of data and materials}

All the data are available in contact with the corresponding author.

\section{Competing interests}

The authors declare that they have no competing interests.

\section{Funding}

No external source of funding was used.

Open Access funding enabled and organized by Permedica S.p.A.

\section{Authors' contributions}

DT: Study initiation, study design, revision of the manuscript, validation. BL: Study design, data analysis, writing of the manuscript, validation. VR: study design, data analysis, writing of the manuscript, validation. LA: study design, supervision, revision of the manuscript, validation.

\section{Acknowledgements}

None

\section{Authors' information}

Domenico Tigani and Luca Amendola: Department of Orthopaedics, Maggiore Hospital, Largo Nigrisoli 2, 40100 Bologna, Italy

Lorenzo Banci and Riccardo Valtorta: Department of Clinical Research and D\&R, Permedica S.p.A., Via Como 38, 23807 Merate, Italy 


\section{References}

1. Australian Report 2020. Orthopaedic Association National Joint Replacement Registry (AOANJRR). Hip, Knee \& Shoulder Arthroplasty. AOA: Adelaide; 2020. pp. 1-474.

2. Cafri G. Paxton EW, Love R. Bini SA, Kurtz SM. Is There a Difference in Revision Risk Between Metal and Ceramic Heads on Highly Crosslinked Polyethylene Liners? Clin Orthop Relat Res. 2017;475(5):1349-55.

3. Bloemheuvel EM. Van Steenbergen LN, Swierstra BA. Low revision rate of dual mobility cups after arthroplasty for acute hip fractures: report of 11,857 hip fractures in the Dutch Arthroplasty Register (20072019). Acta Orthop. 2021;92(1):36-9.

4. Triclot P. Gouin F. Update-"Big-head": the solution to the problem of hip implant dislocation? Orthop Traumatol Surg Res. 2011;97 Suppl 4:42-8.

5. Rodriguez JA. Rathod PA. Large diameter heads: is bigger always better? J Bone Joint Surg Br. 2012;94 Suppl 11:52-4.

6. Bousquet G. Gazielly D, Girardin P. Debiesse JL, Relave M. Israeli A. The ceramic coated cementless total hip arthroplasty. Basic concepts and surgical technique. J Orthop Surg Tech. 1985;1:15-28.

7. Farizon F. De Lavison R, Azoulay JJ. Bousquet G. Results with a cementless alumina-coated cup with dual mobility. A twelve-year follow-up study. Int Orthop. 1998;22:219-24.

8. Charnley J. Kamangar A, Longfield MD. The optimum size of prosthetic heads in relation to the wear of plastic sockets in total replacement of the hip. Med Biol Eng. 1969;7(1):31-9.

9. McKee GK. Watson-Farrar J. Replacement of arthritic hips by the McKee-Farrar prosthesis. J Bone Joint Surg [Br]. 1966;48:245-59.

10. De Martino I. D'Apolito R, Soranoglou VG. Poultsides LA, Sculco PK. Sculco TP. Dislocation following total hip arthroplasty using dual mobility acetabular components: a systematic review. Bone Joint J. 2017;99 Suppl 1:18-24.

11. Dubin JA. Westrich GH. Anatomic dual mobility compared to modular dual mobility in primary total hip arthroplasty: a matched cohort study. Arthroplasty Today. 2019;5(4):509-14.

12. Huang RC. Malkani AL, Harwin SF. Hozack WJ, Mont MA. Higuera-Rueda CA, Westrich GH. Multicenter Evaluation of a Modular Dual Mobility Construct for Revision Total Hip Arthroplasty. J Arthroplasty. 2019;34(7S):287-91.

13. Chalmers BP. Mangold DG, Hanssen AD. Pagnano MW, Trousdale RT. Abdel MP. Uniformly low serum cobalt levels after modular dual-mobility total hip arthroplasties with ceramic heads: a prospective study in highrisk patients. Bone Joint J. 2019;101 Suppl 6:57-61.

14. Markel DC. Bou-Akl T, Rossi MD. Pizzimenti N, Wu B. Ren W. Blood metal levels, leucocyte profiles, and cytokine profiles in patients with a modular dual-mobility hip prosthesis: early results from a prospective cohort study. Bone Joint J. 2019;101(9):1035-41.

15. Nam D. Salih R, Nahhas CR. Barrack RL, Nunley RM. Is a modular dual mobility acetabulum a viable option for the young, active total hip arthroplasty patient? Bone Joint J. 2019;101 (4):365-71.

16. Sariali E. Lazennec JY, Khiami F. Catonné Y. Mathematical evaluation of jumping distance in total hip arthroplasty: influence of abduction angle, femoral head offset, and head diameter. Acta Orthop. 2009;80(3):277-82. 
17. Lewinnek GE. Lewis JL, Tarr R. Compere CL, Zimmerman JR. Dislocations after total hip-replacement arthroplasties. J Bone Joint Surg Am. 1978;60(2):217-20.

18. Rathi P. Pereira GC, Giordani M. Di Cesare PE. The pros and cons of using larger femoral heads in total hip arthroplasty. Am J Orthop (Belle Mead NJ). 2013;42(8):E53-9.

19. Amstutz HC. Le Duff MJ, Beaulé PE. Prevention and treatment of dislocation after total hip replacement using large diameter balls. Clin Orthop Relat Res. 2004;(429):108-116.

20. Hartzler MA. Abdel MP, Sculco PK. Taunton MJ, Pagnano MW. Hanssen AD. Otto Aufranc Award: Dualmobility Constructs in Revision THA Reduced Dislocation, Rerevision, and Reoperation Compared With Large Femoral Heads. Clin Orthop Relat Res. 2018;476(2):293-301.

21. Sutter EG. McClellan TR, Attarian DE. Bolognesi MP, Lachiewicz PF. Wellman SS. Outcomes of Modular Dual Mobility Acetabular Components in Revision Total Hip Arthroplasty. J Arthroplasty. 2017;32(9):220-4.

22. Tarity TD. Koch CN, Burket JC. Wright TM, Westrich GH. Fretting and Corrosion at the Backside of Modular Cobalt Chromium Acetabular Inserts: A Retrieval Analysis. J Arthroplasty. 2017;32(3):1033-9.

23. Lombardo DJ. Siljander MP, Gehrke CK. Moore DD, Karadsheh MS. Baker EA. Fretting and Corrosion Damage of Retrieved Dual-Mobility Total Hip Arthroplasty Systems. J Arthroplasty. 2019;34(6):1273-8.

24. Kolz JM. Wyles CC, Van Citters DW. Chapman RM, Trousdale RT. Berry DJ. In Vivo Corrosion of Modular Dual-Mobility Implants: A Retrieval Study. J Arthroplasty. 2020;35(11): 3326-9.

25. Chalmers BP. Dubin J, Westrich GH. Modular Dual-Mobility Liner Malseating: A Radiographic Analysis. Arthroplast Today. 2020;6(4):699-703.

26. Romero J. Wach A, Silberberg S. Chiu YF, Westrich G. Wright TM, Padgett DE. 2020 Otto Aufranc Award: Malseating of modular dual mobility liners. Bone Joint J. 2020;102 Suppl 7:20-6.

27. Affatato S. Castiello E, Amendola L. Comitini S, Prudhon JL. Tigani D. Revision of a Monoblock Metal-onMetal Cup Using a Dual Mobility Component: Is It a Reasonable Option? Materials. 2020;13(9):2040.

28. De Smet K. Van Der Straeten C. Design issues and comparison of hip resurfacing prostheses. In: De Smet, K, Campbell PN. Van Der Straeten C editors. The Hip Resurfacing Handbook. A practical guide to the use and management of modern hip resurfacings. Woodhead Publishing: Cambridge;2013 p. p. 88.

\section{Tables}

\section{Table 1}

Dimensional comparison of the selected prosthetic components, matched for same cup size. 


\begin{tabular}{|c|c|c|c|c|}
\hline $\begin{array}{l}\text { Cup size } \\
\text { (external } \\
\text { cup Ø) } \\
{[\mathrm{mm}]}\end{array}$ & $\begin{array}{l}\text { Ext-Int } \varnothing \text { of PE } \\
\text { mobile liner to be } \\
\text { used with Acorn } \\
\text { Traser® DM cup } \\
\text { [mm] }\end{array}$ & $\begin{array}{l}\text { Ext-Int } \varnothing \text { of PE mobile liner to } \\
\text { be used with Jump System } \\
\text { Traser } ® \text { cup and modDM } \\
\text { liner } \\
{[\mathrm{mm}]}\end{array}$ & $\begin{array}{l}\text { modDM } \\
\text { metal liner } \\
\text { size } \\
\text { (colour } \\
\text { code) }\end{array}$ & $\begin{array}{l}\text { Femoral } \\
\text { head } \varnothing \text { compatible with } \\
\text { Jump System } \\
\text { Traser® and FB liner } \\
\text { [mm] }\end{array}$ \\
\hline 48 & $40-28$ & $38-28$ & $\begin{array}{l}48-50 \\
\text { (yellow) }\end{array}$ & 28,32 \\
\hline 50 & $42-28$ & $38-28$ & $\begin{array}{l}48-50 \\
\text { (yellow) }\end{array}$ & 28,32 \\
\hline 52 & $44-28$ & $40-28$ & $\begin{array}{l}52-54 \\
\text { (grey) }\end{array}$ & $28,32,36$ \\
\hline 54 & $46-28$ & $40-28$ & $\begin{array}{l}52-54 \\
\text { (grey) }\end{array}$ & $28,32,36$ \\
\hline 56 & $48-28$ & $44-28$ & $\begin{array}{l}56-60 \\
\text { (blue) }\end{array}$ & $28,32,36,40$ \\
\hline 58 & $50-28$ & $44-28$ & $\begin{array}{l}56-60 \\
\text { (blue) }\end{array}$ & $28,32,36,40$ \\
\hline 60 & $52-28$ & $44-28$ & $\begin{array}{l}56-60 \\
\text { (blue) }\end{array}$ & $28,32,36,40$ \\
\hline 62 & $54-28$ & $46-28$ & $62-64$ (red) & $28,32,36,40$ \\
\hline 64 & $56-28$ & $46-28$ & $62-64$ (red) & $28,32,36,40$ \\
\hline
\end{tabular}

Table 2

Offset results for DM, modDM and FB with compatible femoral head diameters matched for same cup size. 


\begin{tabular}{|c|c|c|c|c|c|c|c|}
\hline Cup size & DM & DM & $\operatorname{modDM}$ & $\operatorname{modDM}$ & FB & FB & FB \\
\hline Ext. $\mathbb{E}[\mathrm{mm}]$ & $\begin{array}{l}\text { Poly mobile } \\
\text { liner } \\
\text { ext. } \mathbb{E}[\mathrm{mm}]\end{array}$ & $\begin{array}{l}\text { Offset } \\
\mathrm{AE} \\
{[\mathrm{mm}]}\end{array}$ & $\begin{array}{l}\text { Poly mobile } \\
\text { liner } \\
\text { ext. } \mathscr{E}[\mathrm{mm}]\end{array}$ & $\begin{array}{l}\text { Offset } \\
\mathrm{AE} \\
{[\mathrm{mm}]}\end{array}$ & $\begin{array}{l}\text { Femoral } \\
\text { head } A E[\mathrm{~mm}]\end{array}$ & $\begin{array}{l}\text { Offset CE } \\
\text { with } \\
\text { polyethylene } \\
\text { liner [mm] }\end{array}$ & $\begin{array}{l}\text { Offset } \\
\text { CE with } \\
\text { ceramic } \\
\text { liner } \\
\text { [mm] }\end{array}$ \\
\hline 48 & 40 & -2.4 & 38 & 1.0 & $28 ; 32$ & $-1 ;-1$ & $-1 ;-1$ \\
\hline 50 & 42 & -2.4 & 38 & 1.1 & $28 ; 32$ & $-1 ;-1$ & $-1 ;-1$ \\
\hline 52 & 44 & -2.3 & 40 & 1.2 & $28 ; 32 ; 36$ & $-1 ;-1 ;-1$ & $-1 ;-1 ;-1$ \\
\hline 54 & 46 & -2.3 & 40 & 1.2 & $28 ; 32 ; 36$ & $-1 ;-1 ;-1$ & $-1 ;-1 ;-1$ \\
\hline 56 & 48 & -2.3 & 44 & 2.0 & $28 ; 32 ; 36 ; 40$ & $-1 ;-1 ;-1 ;-1$ & $\begin{array}{l}-1 ;-1 ; 0 ; \\
2\end{array}$ \\
\hline 58 & 50 & -2.4 & 44 & 2.0 & $28 ; 32 ; 36 ; 40$ & $-1 ;-1 ;-1 ;-1$ & $\begin{array}{l}-1 ;-1 ; 0 ; \\
2\end{array}$ \\
\hline 60 & 52 & -2.4 & 44 & 2.0 & $28 ; 32 ; 36 ; 40$ & $-1 ;-1 ;-1 ;-1$ & $\begin{array}{l}-1 ;-1 ; 0 \\
2\end{array}$ \\
\hline 62 & 54 & -2.2 & 46 & 3.0 & $28 ; 32 ; 36 ; 40$ & $-1 ;-1 ;-1 ;-1$ & $\begin{array}{l}-1 ;-1 ; 0 \\
2\end{array}$ \\
\hline 64 & 56 & -1.9 & 46 & 3.0 & $28 ; 32 ; 36 ; 40$ & $-1 ;-1 ;-1 ;-1$ & $\begin{array}{l}-1 ;-1 ; 0 ; \\
2\end{array}$ \\
\hline
\end{tabular}

Figures 


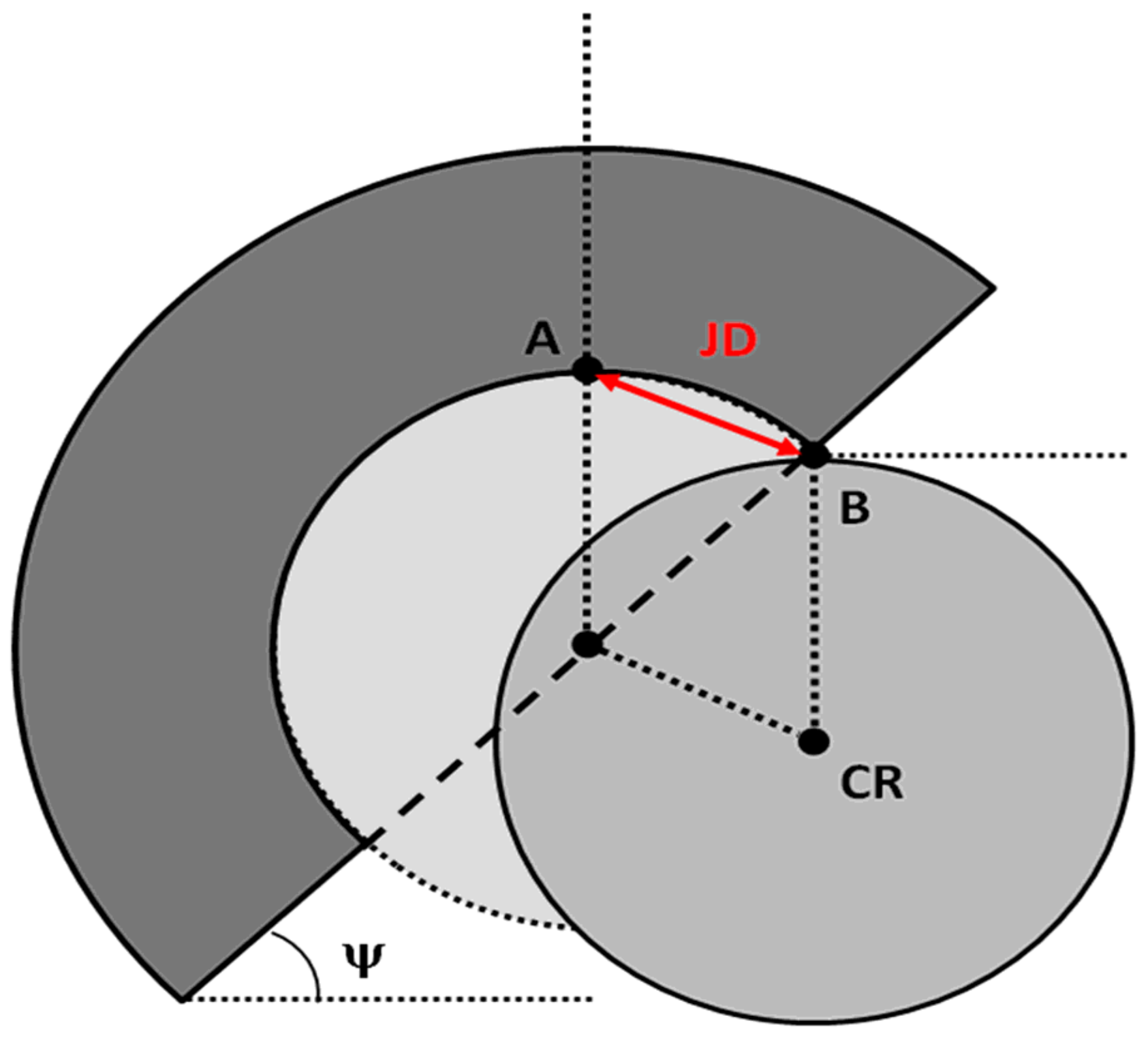

Figure 1

Jumping distance (JD) is defined as the lateral translation distance $A B$ of the femoral head center (CR) required for a femoral head to dislocate from an acetabular socket. 


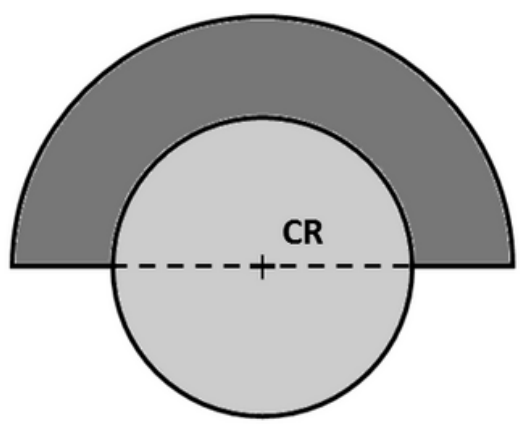

A

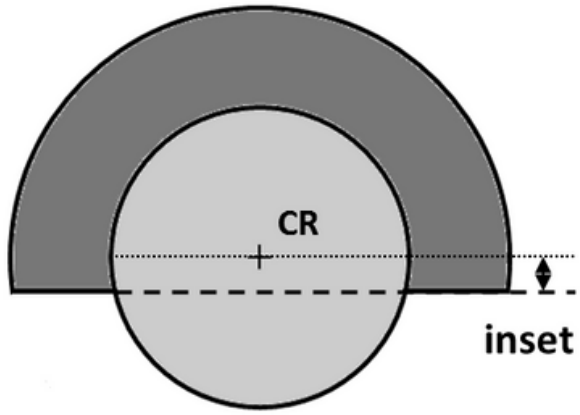

B

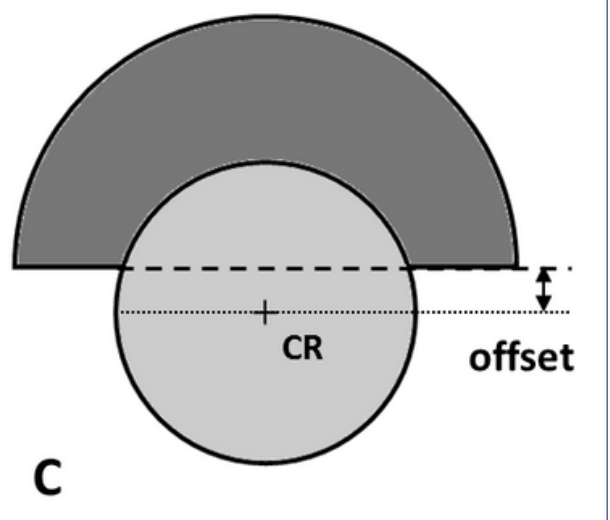

Figure 2

Offset of the femoral head is defined as the distance between the femoral head center (CR) and the cup opening plane. Femoral head offset: neutral (A), negative or inset (B) and positive (C).

A

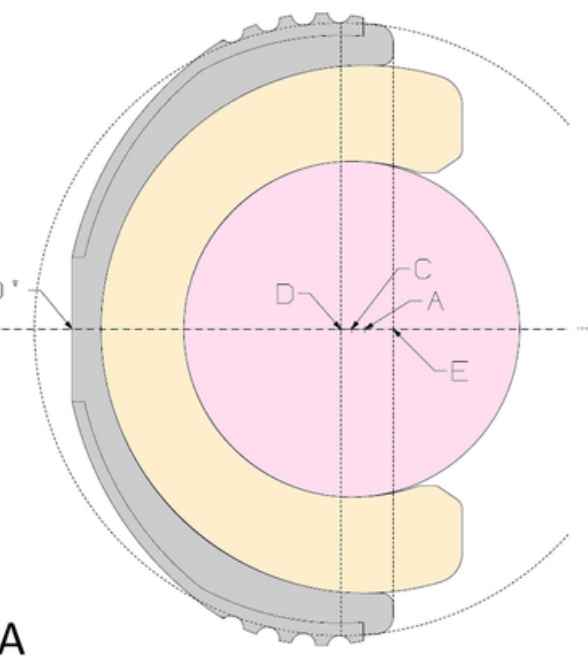

B

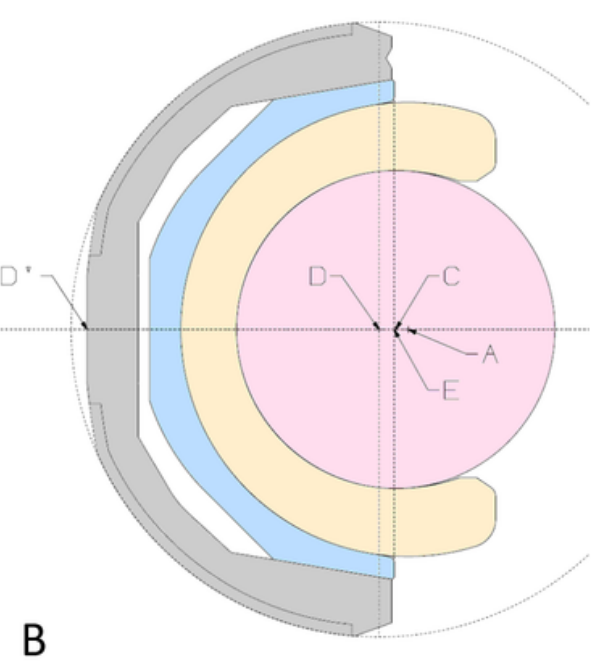

C

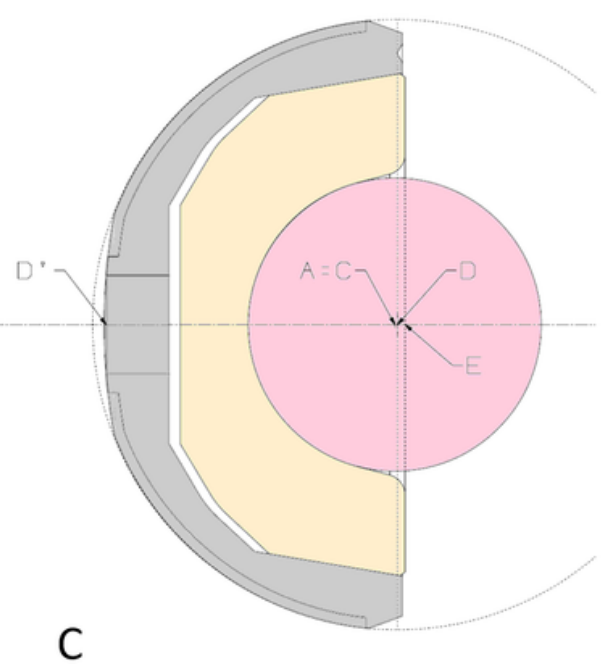

Figure 3

A, DM cup. Cross-sectional drawing of Acorn Traser® DM cup by Permedica S.p.A. B, ModDM system. Crosssectional drawing of Jump System Traser ${ }^{\circledR}$ cup with modDM liner by Permedica S.p.A. C, FB cup. Crosssectional drawing of Jump System Traser ${ }^{\circledR}$ cup with FB liner. Dashed lines represent the cup opening plane and the ideal spherical profile outlining the external cup profile in the press-fit equatorial area. A: Center of the polyethylene mobile liner (center of rotation of the mobile liner). C: Center of femoral head (CR of the femoral head). D: Center of the ideal spherical cup outer profile. D': point of the cup polar apex, corresponding to the intersection between the outer cup profile and the cup axis. E: intersection point between the cup opening plane and cup axis. 


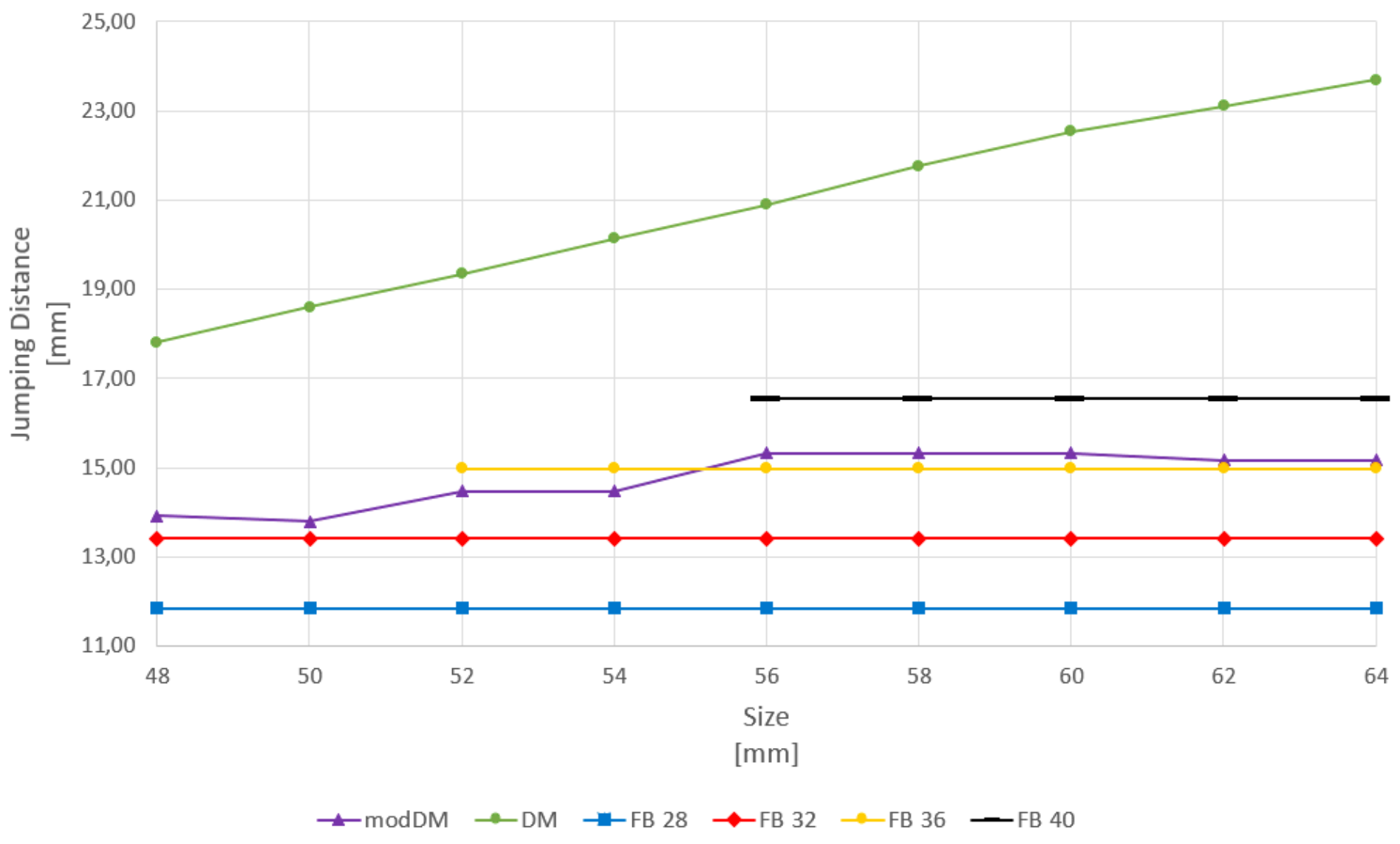

Figure 4

JD for DM, modDM and polyethylene FB coupled with $28 \mathrm{~mm}, 32 \mathrm{~mm}, 36 \mathrm{~mm}, 40 \mathrm{~mm}$ femoral head diameters per cup size. 


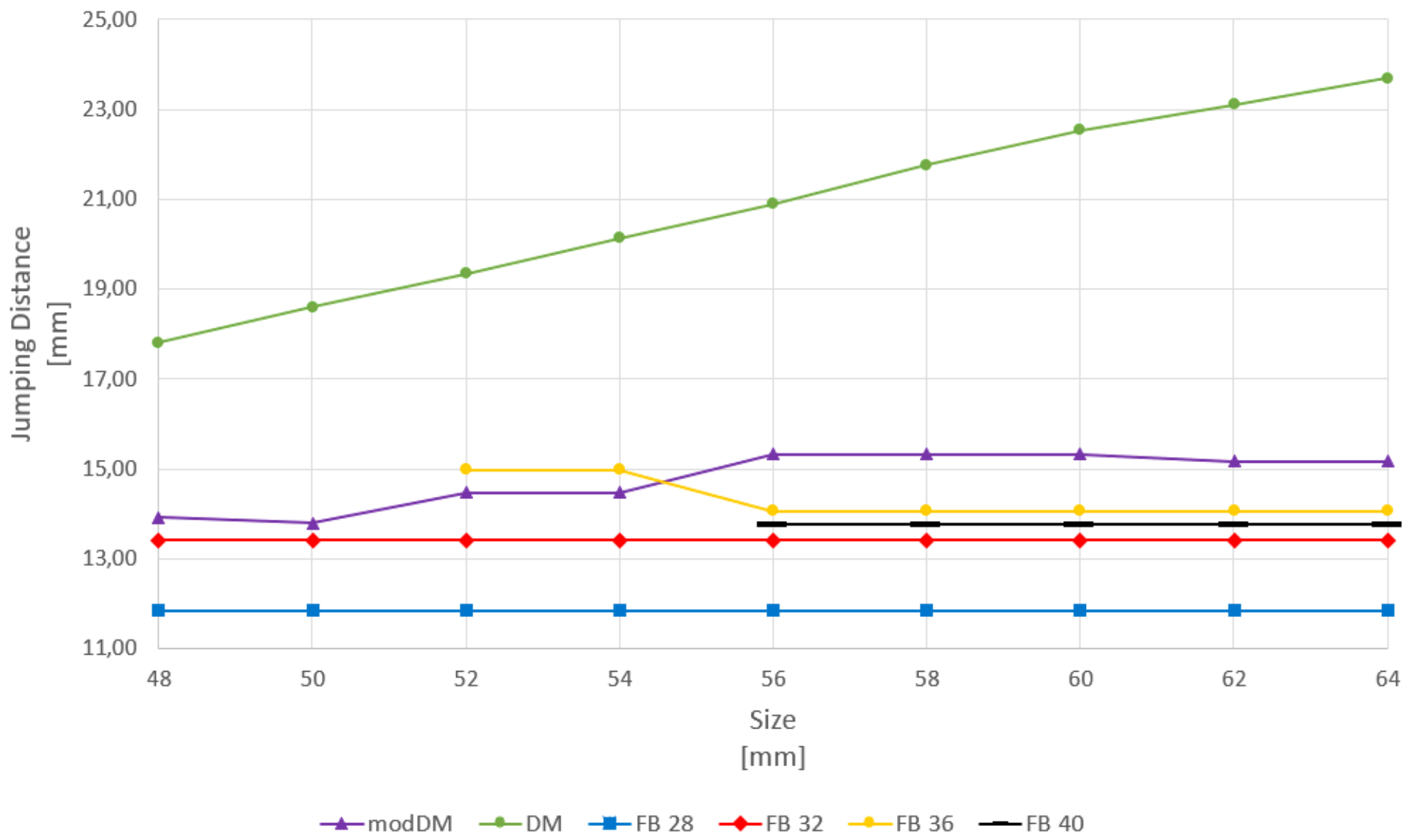

Figure 5

JD for DM, modDM and ceramic FB coupled with $28 \mathrm{~mm}, 32 \mathrm{~mm}, 36 \mathrm{~mm}, 40 \mathrm{~mm}$ femoral head diameters per cup size. 


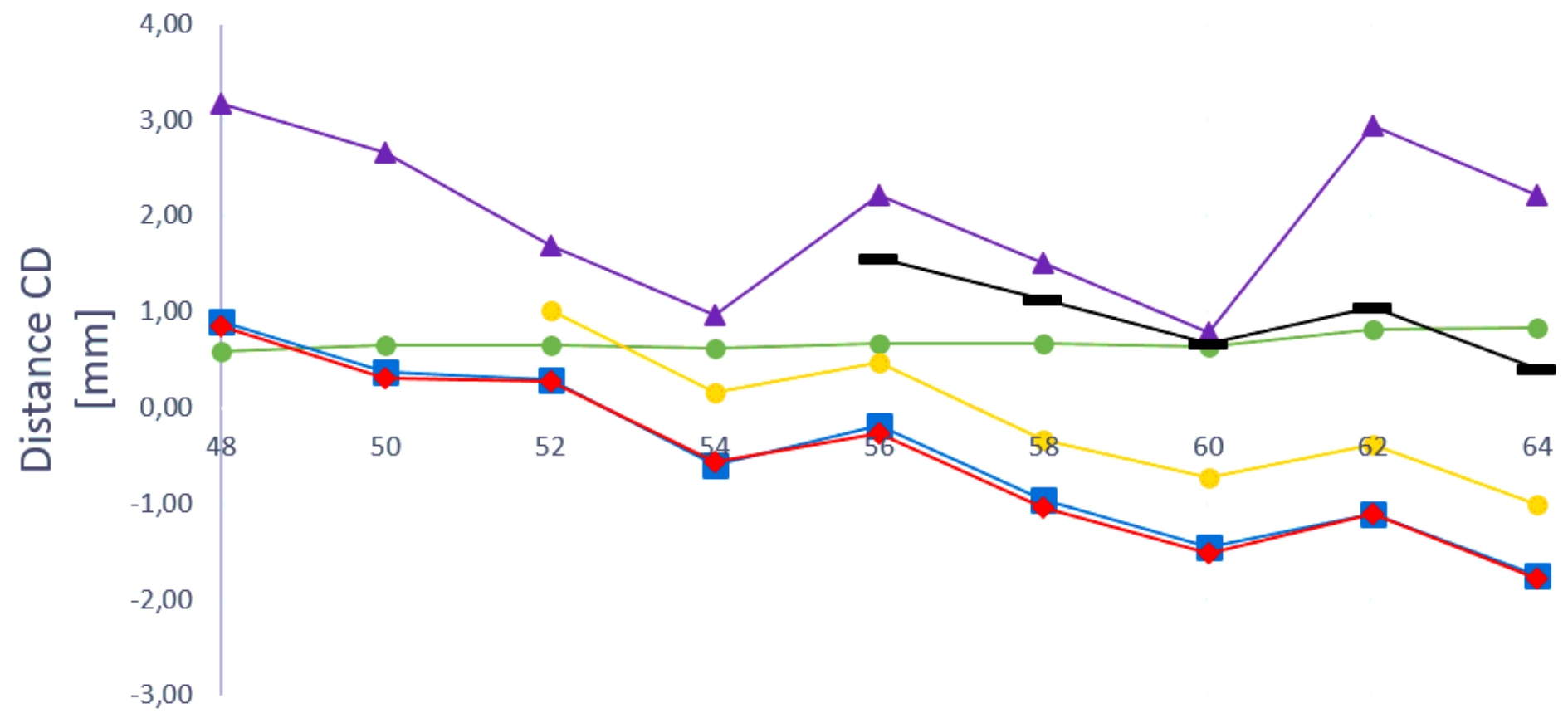

Size

$[\mathrm{mm}]$

$\rightarrow$ DM $\leftarrow$ modDM $\rightarrow$ FB $28 \rightarrow-F B 32 \multimap-F B 36-$ FB 40

Figure 6

CD distance for DM, modDM and FB cups, per cup size. $C D$ distance for FB with $36 \mathrm{~mm}$ and $40 \mathrm{~mm}$ femoral head diameters were only for ceramic liners. 